\title{
Medium Rare: Exploring Archives and their Conversion from Original to Digital
}

\section{Part One: Lessons from the History of Print Media}

\author{
by \\ Kiersten F. Latham, Ph.D. \\ Kent State University \\ Kent, $\mathrm{OH}$ \\ kflatham@kent.edu
}

\begin{abstract}
This paper, which will be published in two parts, explores the physicality of archival materials in the context of the digital age. This first part reviews key lessons in the history of new technologies that have affected archival practice. The issues and problems we now face with conversion of physical archives to digital form are not entirely new. Throughout time, humans have gone through similar major transformations which affected not only culture and behavior but cognition in relation to information acquisition - the conversion from oral transmission to written or from locally available written media to mass-produced forms of communication are examples. This article provides a brief review of these historical processes and gives an overview of some of the lessons we can learn from them. Part Two (which will be published in the March 2011 issue of LIBRES) will explore a holistic understanding of paper-based knowledge transmission—specifically archives—in the context of the digital access movement.
\end{abstract}

\section{Introduction}

"People don't actually read newspapers. They step into them every morning like a hot bath."

--Marshal McLuhan

This very insightful quote from the man who purported that "the medium is the $\mathrm{m}[\mathrm{e}] \mathrm{ssage"}$ "tells us worlds about the physical remains of our textual paper-based information. McLuhan (1962), the Canadian media theorist of the late 20th century, believed that media are "extensions" of our human senses, bodies and minds; in other words, the means by which humans communicate determines our very thoughts, actions, and life (McLuhan, 1964). McLuhan explored the historical changes in the communication medium from orally transmitted knowledge to print culture introduced with the Gutenberg press, and more recently, to electronic means of transferring information. The cultures associated with knowledge transmission-oral, manuscript, print, electronic, and digital—are at the core of understanding what happens when physical paper-based media are converted to a digital form. The relationship between humans and physical objects is also important to the understanding of this shift. Paper-based knowledge always has a physical form - a three-dimensional, textural quality — and this aspect of what occurs in the process of using the material must be considered. Archives especially are endowed with many layers of physical elements, from the paper, the ink, handwriting versus type, stains, 
doodles, binding style, and on. They are also unique in that their order and relationship within the sets of other papers and files have meaning. The human-object relationship is rich as well as complex and involves issues of value, meaning, experience and process - all of which will be discussed in this paper series. These relationships, elements, and processes, in turn, all have an effect on the information transfer process and what kind of information do and do not transfer.

I have two main concerns for the future of archives regarding this topic. As archives become more accessible online, fewer researchers will be physically handling original archival material. Is some sort of information or knowledge lost when original materials are not usedphysically handled-by researchers? In addition, I am concerned for the fate of "real" materials once they have been digitized. Nicholson Baker's (2001) book, Double Fold, about American libraries' nearly fatal destruction of all historic newspapers, has brought to the surface questions about what it means to transform an original work on paper into a new format. In this paper series, I hope to emphasize the importance of keeping the "real thing" so that we do not have similar disastrous results as we have had with American newspapers.

The main contention, then, revolves around this: What is available to a researcher of original archival material that may not be accessible in the digital form? This central question in turn addresses these three questions: 1 ) what is lost in the process of converting original archival material to digital form?; 2) is there something unique in the live interaction with original material?; and 3) what do original materials transfer to the user that the digital fails to provide.

This paper does not argue against the obvious positive elements of digitizing archives when it comes to access. Clearly, the posting of materials to the internet allows much greater accessibility to archival material and therefore more widespread transmission of information that has previously been difficult to access. Rather, the questions this paper addresses are very focused, honing in on precisely what kind of trade-offs there may be when the original materials are (potentially) no longer what is accessed. This paper also does not attempt to investigate, in detail, the elements of the digital form of archives. Discussion of digital material is limited to the contrast with original materials.

The structure of this paper begins with a broad discussion of the digital issue surrounding archival material. Archives are then defined and the notion of paper-based knowledge transmission is presented. Lessons from other paper-based material are then reviewed-the book and newspapers, followed by a brief discussion of current research on digital libraries. The central topic, that is, the unique features of archives and researching these material, are then presented in detail in part two of this series. Aspects of both the physicality of archival materials and the experiential components of archival research are reviewed. Finally, the information presented above will come together in a discussion about the potential effects on the information transfer process.

\section{The digitization of everything?}

The digitization movement is ubiquitous and now well-entrenched. All one needs to do is review the trends in library and information studies, museum studies, and other memory institutions - and take note of the many grants available to those with digitization projects. There 
is an overall glow to the language describing these endeavors, as the following comment from a Sun Microsystems brochure entitled, “Digital Library Technology Trends” illustrates:

The library, historically a cornerstone of scholarly endeavor, is reinventing itself in today's networked society to meet these new demands. Instead of a building that holds books, the library is evolving into an electronic portal to a growing global collection of digital content. The doors to this virtual library are now open 24 hours a day, seven days a week, and the library's holdings come to the user when needed. Today's library includes sophisticated tools that make it easy to find the best information resources, delivering them to one's desktop or mobile computing device at the push of a button.- (Wright, in Sun Microsystems, 2002, p.i).

The emphasis of this movement is on access and the incredible shift in both the amount and speed with which information can be acquired. Even the user studies - where concern is shown for the effects of using digital copies of original materials might mean to the user-tend to hone in on access issues and ignore actual experiential outcomes. Surprisingly (or maybe not so surprisingly), there are very few vocalizing a concern for the rapidity of this shift; very few who are questioning it and taking the time to ask: What might be lost in this process? The question is usually How much can we digitize? rather than Should we digitize?

This switch to a digital means of transmitting knowledge is no small issue. When there is a change in the form of transmitting information, all aspects of culture and cognition are affected (Eisenstein, 1979; McLuhan, 1964; Ong, 1982). The historical changes in communication form are well documented. Generally, western thought has historically changed format in the following order: oral, manuscript, print, electronic, and now digital. Clearly, elements of the previous forms of communication are retained even with the new emphasis being placed on emerging technologies. Time and time again, we have experienced this major shift in form of knowledge transfer, yet we seem to ignore lessons from the past.

\section{What is paper-based knowledge transmission?}

Archives are, mostly, a type of material from the print culture ${ }^{1}$. The use of archives, then, is a form of paper-based knowledge transmission. In this form of information transfer, knowledge is distributed and disseminated via writing (of any form) on a paper medium. Other carriers of paper-based knowledge are books, newspapers, letters, manuscripts, magazines, maps, and pamphlets, to name a few. Examples of materials that are not considered paper-based are microfiche, microfilm, compact discs, audio tapes - although each of these may be classified under the rubric of print culture. One important feature of paper-based materials is that they require no conversion, or translation, in order to read them (Smith, 2005). The largest American organization for archival work is the Society of American Archivists (SAA). They define an archive as:

Materials created or received by a person, family, or organization, public or private, in the conduct of their affairs and preserved because of the enduring value contained in the information they contain or as evidence of the functions and responsibilities of their creator, especially those materials maintained using the principles of provenance, original order, and collective control; permanent records (SAA, 2007, n.p.).

\footnotetext{
${ }^{1}$ This is not to say that audiovisual or other forms of archives are not valid. My intent is to point out that the bulk of material is paper-based and my focus in this paper is on that material.
} 
For the purposes of this paper, the term archives is used to describe archival collections, records, photographs, visual material, and ephemera. Although audiovisual materials could be included in this discussion, the focus of this paper is on paper-based material that does not require a machine to decipher its contents. Archives, as outwardly physical manifestations of human production (Foote, 1988), are considered to be “objects" of human culture. Therefore, since my perspective of these print-based materials is another form of object, I will occasionally refer to them as such. Additionally, I will not treat records differently from manuscript materials; they are all archives.

\title{
Lessons from other printed material
}

With regard to what certain kinds of printed material can tell us-beyond contentscholars of archival theory are somewhat lacking in the discussion of their importance. However, there are two genres of printed material in which extensive discussion about these issues has been prolific: newspapers and books. The destruction of America's original historical newspaper collections was the topic of Nicholson Baker's highly debated book, Double Fold: Libraries and the Assault on Paper (2001). His book sparked a debate and great discussion, in the context of a world bound for digitization, about the importance of paper originals. The emerging discussions were intense enough to bring together academics, librarians, and preservationists on listservs, in articles, meetings and symposia (Carignan, DuMerer, Koutsky, Lindquist, McClurken \& McElrath, 2005). One such conference was held at the University of Maryland in 2002 entitled, “Who Wants Yesterday’s Papers?” The conference was so popular that the organizers actually had to turn people away and three years later, a book of the same name was published based on the symposium (Carignan et al., 2005). These two works together equal a rich source of current views on what originals mean to us. For the most part, the emphasis is on books and newspapers. The lessons these writings teach are highly appropriate for our questions about knowledge transmission in archival material. After all, all three types of material are forms of paper-based knowledge. The thoughts, concerns and ideas presented to us about books and newspapers in order to later apply these issues to archives are discussed in the following section.

\section{Book Lessons: The Embodied Text}

\begin{abstract}
What do books want from us? Let us forget for a second the impossibility of this question and suppose that our books might not be so very different from us, that they want long and happy lives, with adequate shelter and first-rate health care. We might even suppose that they want to be recognized for the unique histories they each bear and that_-very much like us - they above all want understanding, to speak, and to be heard. For, of course, books speak volumes — even when few of us are listening (Fraistat, 2005, p. 59).
\end{abstract}

As one of the contributors to the symposium, "Who Wants Yesterday’s Papers?,” Neil Fraistat turns the problem on its head and argues from the book's "point of view”. He believes that books "speak to us" as material objects, with more to give than just data or information. Words in books, says Fraistat, are always embodied "in the company of other kinds of material signs” (2005, p.60), that require us to accept the multiplicity and significance of those signs When referring to the remediation of books or newspapers into another format, such as microfilm or digital, we are talking about a form of translation, a "change in state that inevitably alters a multiplicity of meanings" (2005, p. 59). Lindquist (2005) calls books, "the technology, the form of knowledge that preserves many other forms of knowledge," and claims that it is the "most important instrument, of human progress," (pp. 6-7). 
McGann, in a relatively new subfield, textual studies, has introduced two interesting concepts that are unique about the book: bibliographical codes and linguistic codes (1991). Bibliographical codes include page format, paper, typefaces, size, shape, cover design, color, price, advertising mechanisms, illustrations, and decorations to name a few. Linguistic codes include the linguistic text proper but also the sets of surrounding paratexts such as prefaces, footnotes, dedications and the like (Fraistat, 2005). McGann points out that all texts are socially and historically relative and we must pay attention to their "relations" and "relativities" (1991, p. 93). Referring to the physical evidence in "books (and all other artifacts)," Tanselle (2005, p. 156) notes that they can provide two types of information beyond content: that of the production of the material, and that of the use of the material, or, as he puts it: “...the light it sheds on how the objects were conceived and produced, and the insight it offers on how the objects have been responded to and treated since the time they left their producers’ hands” (2005, p.156).

Tanselle (2005) cites many fine details about what can be learned from the original book. For example, the identification of broken types and the traces of the typeface impression itself within the total ink smear tells us the order in which pages were set and printed. The indentations made in the paper by the "bite" of the type can reveal the order in which the two sides of a sheet were printed. These are all elements that cannot be seen in any copy. Analysis of such things are important to the study of printing history, literary history, textual study, and dating a book (Tanselle, 2005).

John Swan (1988) points out that the translation (to use Fraistat's term) from printed material to an electronic form is a "decontextualization and disembodiment" (Fraistat, 2005, p. 108) of the printed work something that is "an inevitable part of the electronic metamorphosis of information" (Fraistat, 2005, p. 108). In other words, there is a relationship between the material nature of the printed work and the information contained therein. A portion of information that books hold, perhaps tacit to most of us, is lost when the translation occurs. In regard to this issue, Gass believes that it is not simply the information in books that matters but "how the information is arranged, how it is understood, and to what uses it is put. In short, what matters is the book the data’s in” (1999, as cited in Cybulski, 2005, p.108).

In a study done for the Modern Language Association (MLA), Phyllis Franklin (2005) surveyed its members regarding the importance of primary records-books, rare books, and archives. She found that the respondents felt electronic versions were useful to them but maintaining originals was vitally important to their continuing scholarship. The members gave four reasons for maintaining materials of the print era: 1) because it is subject of the traditional work done by bibliographers, textual editors and literary critics; 2) copies are often unstable and unreliable so originals should always be kept; 3) the materiality of the text is seen as evidence of the audiences they were designed to serve; and 4) for those who study the history of the book. Still others were concerned that the field itself would change if originals were not kept. As one respondent stated, "[F]or the real work of preserving the cultural heritage, which is not to keep it dead but alive,...the continuing presence of the original objects [is essential]” (Jehlen, as cited in Franklin, 2005, p.117). The MLA was so concerned about potential loss that they created a "Statement on the Significance of Primary Records" in 1995. The statement is long, but one section is worth repeating here: 
...Texts are inevitably affected by the physical means of their transmission; the physical features of the artifacts conveying texts therefore play an integral role in the attempt to comprehend those texts. For this reason, the concept of a textual source must involve attention to the presentation of a text, not simply to the text as a disembodied group of words... The existence of community libraries along with academic libraries has been, and will continue to be, essential for bringing historical embodiments of texts-and the sense of the past they impart--to a wide readership. The loss of any copy of any edition--from the earliest incunables to the latest paperback reprints (regardless of whether its text is considered interesting or consequential at the present time)--diminishes the body of evidence on which historical understanding depends (MLA, 1995, n.p.; author's italics).

To summarize, the statement lists roughly eight specific scenarios that justify the continued maintenance of primary records:

1. The same texts, but different version of it, each provide information with their own unique characteristics; each affects a different "historical moment."

2. The object is primary as a source for one purpose but may be different for another purpose.

3. A primary resource is a physical object produced or used at a particular past time.

4. Physical clues reveal facts about how an item was produced.

5. Elements of a book's physical design can be significant indicators of how the text was regarded by its producers and interpreted by its readers.

6. Editions differ and copies within editions differ. Every copy is a potential source of new physical evidence.

7. Since external characteristics affect readers' responses, access to physical forms of past texts is a fundamental part of reading/teaching.

8. Accuracy and stability of reproductions can never be guaranteed.

Cybulski (2005) summarizes the justification for keeping original material in a slightly different manner. He says:

Among the reasons for justifying the continued retention of our print heritage, we might include the observation that they serve as unchanging landscapes of preserved context, where excerpts, citations, factoids, and fragments can be tracked down by skilled bibliographer hunter-gatherers and observed, as it were, in their natural habitats. Another reason is, quite simply, that books are what they are, a superb medium for the transport of ideas, dreams, and stories that has served human readers well for centuries, and will continue to do so for centuries to come (p. 109).

Cybulski also makes the point that librarians, in dealing with an increasing demand for quick access, may need to "cultivate public awareness about the enduring value of print collections, stressing the need to preserve them" (2005, p.100). He goes on, "it should be made abundantly clear that print collections are not unwanted baggage left behind on the roadside where the information highway begins” (2005, p.100). In other words, in the fast-paced environment in which we find ourselves, librarians, and others who deal with textual material, should not only themselves recall the importance of the book, but should not let that fact slip by their patrons. In fact, the MLA, in their statement, also holds workers responsible for helping to shape the attitude of the user regarding printed materials. From their statement:

...the attitudes that people hold about them can be instrumental in either mitigating or exacerbating the destructive effects of these factors. As more people come to see the importance of primary records, more use will be made of them in reading and teaching, and more constituencies will join together in the 
search for ways of financing artifactual preservation, storage, and access. More records will then be saved because there will be wider support for the allocation of resources to this purpose. Decisions about priorities for preservation will still have to be made, by individual as well as institutional owners of material, but those decisions will be reached in a framework that recognizes the artifactual value of every object (MLA, 1995).

Saving the book for the scholars is one thing, but what about the readers? Tanselle (2005)points out that the look and feel of a book affects reading and "all who wish to experience texts with as much historical understanding as possible require the objects that survive from particular past times" (p.159). The experience of reading an electronic version of a book is simply not the same experience as reading and holding the real thing (Lanham, 1993; Lynch, 2001).

\title{
Newspaper Lessons: Lost in Translation
}

\begin{abstract}
...Newspapers ... provide a unique and readily accessible glimpse of the unfolding nature of events. They indicate that state of knowledge or of public opinion at a given time, that no amount of subsequent analysis and more considered reflection can provide. Newspapers are not merely historical sources for academics, but have an equally important role in education and for all that are interested in the past (Stoker, 1999, p.133).
\end{abstract}

The loss of America's original newspapers is a story bigger than space permits. While there are many issues surrounding the translation of newspapers to another medium, there are two specific problems that relate to the questions in this paper. The first problem revolves around the translation of original newspapers to microforms and the subsequent results of that conversion with respect to the research process. The second problem involves the subsequent destruction in the wake of reformatting that newspapers have endured. Both issues have been in the minds of librarians, preservationists and archivists for many years, but the recent upsurge in discussion was prompted by Nicholson Baker's book, Double Fold: Libraries and the Assault on Paper (2001). Baker passionately argues for the preservation of original newspapers and chronicles the extensive destruction of originals by libraries across the world, resulting, in some cases, in a total loss of not only the material, but the information itself. While the accuracy of his story is questioned by some (Carignan et al., 2005), his argument has nevertheless stirred a renewed communication of an important and timely topic. While we are in the midst of an extensive communication revolution (Deuze, 2006) by means of digital facsimiles (and sometimes digital originals), the historical accounts of what has happened to newspapers is vital to our decision-making on the future of all printed material.

Baker (2001) points out that in the translation from original to microfilm, the following problems have occurred:

- the reformatted material, microfilm, can be more unstable than paper unless kept in a well-controlled environment;

- the copied material is often difficult to read, hard to place in context (format), and does not reproduce photographs and illustrations very well (if at all);

- quick, mass copying of newspapers has resulted in copies with missing pages, sections, and editions (that can never be retrieved since they have been destroyed);

- items that were originally in full color are now black \& white;

- materials requires a machine to read it rather than using just the human eye;

- the format meant for newspaper viewers (layout design) is lost to the reader; 
- physical searching of microfilm is cumbersome.

From my own experience as a researcher and a curator of these types of materials, I find all of his points are correct. Together, the problems add up to some serious issues in what is called "preservation reformatting." As mentioned earlier, reformatting is a translation (Fraistat, 2005), and a researcher is always left with something a little less than what the original had to give (Brush, 2005; Cybulski, 2005; Franklin, 2005; Tanselle, 2005). As Newhagen (2005) states about newspapers, " the only original is the original, and any reproduction will in some way be distanced from it” (p. 78). His content analysis study of original versus microfilmed copies of newspapers demonstrates that the medium in its physical form can have a major effect on the outcome of the research query. Newhagen shows that the physical composition of the newspaper-its format, layout, structure, and graphical contents-conveys additional meaning (information) to the reader beyond simple text. Newspapers employ a psychological user model that allows the reader to take in maximum amount of content while expending minimal cognitive effort in topic selection. Furthermore, "newspapers were never meant to be read from front to back” (2005, p. 77). A great example of the effect of formatting and typographical details is revealed in a classroom exercise Fraistat (2005) presents. The students were to transpose the contents of the Wall Street Journal with those of the National Enquirer, leaving each with its own style and format. They swapped headlines with format: "Two-headed Boy Gives Birth to Alien Savior with Telepathic Knowledge of Biblical Past Lives” was presented in the subdued, modestly composed structure of the Wall Street Journal; and "Bond Markets See Rates Drop by Slight Margin” was presented in the very bold, “screaming” way the Enquirer tends to present its material (2005, p. 60). Imagine the result.

Ultimately, worse than the fate of the copy, is the fate of the original itself. Baker (2001) is not inherently against microfilming, but preservation microfilmers, he says, have sacrificed the original in order to create the copy by means of disbinding the original (in the interest of creating a better copy). One method was called "guillotining," and employed the act of slicing off the binding in one motion, forever rendering the original useless for rebinding. Another act that intensely disturbed Baker was that newspapers not destroyed after guillotining were sold to dealers who subsequently cut them up (and threw the rest away) to sell particularly desirous pieces to collectors such as Coke adds and stories of famous events (Baker, 2001).

Newhagen (2005) takes a slightly different approach and looks at the results of microfilming on content analysis, a research technique used to describe the content of communication. Content, in his analysis, includes all coding, including the appearance of text, the physical dimensionality of the record (as it originally appeared), and the psychological effects of meaning imbued in these features. "Above the fold” carries great meaning in the newspaper world; items that appear in this location have been assigned greater overall importance as bits of information. Readers of English text scan from left to right, and the most vital story will likely appear on the upper left corner of the paper. The size and format of the page can convey information about social class of the reader as well. As Fraistat (2005) describes it:

In newspapers’ heyday most cities supported at least one morning and one afternoon paper. Typically the morning paper was a smaller, more manageable tabloid that was easier to read at the breakfast table, on the subway on the way to work, or on the job. The more cumbersome broadsheets, which could be read in the parlor easy chair, dominated the afternoon market. Thus, tabloid newspapers came to be 
associated with the working class, who read them in the morning, while broadsheets were more intellectual and tended to be read by the middle class at home in the evening (p. 80).

One can also gather information about gender from original format newspapers (Fraistat, 2005). A simple review of descriptors used to describe female politicians - whether in reference to physical attributes or to describe what they have to say — would not produce appropriate results. Size of text and location within the paper (emphasis), plus reader tendencies ${ }^{2}$ also provide information about the importance of different portions of content in the paper. A typical content analysis would treat words at the beginning of the article the same as words at the end but, in reality, they do not weigh equally in terms of importance (Fraistat, 2005).

\section{Lessons from digital libraries: is access everything?}

In recent years, there has been a proliferation of digitally available (archival) material. Much of the research on user experience in this area tends towards instrumental aspects of use and tells us that access outweighs most other factors. Although user studies comparing paper versus digital versions of material have been done, there are relatively few studies that provide insight into the physical and related psychological aspects of use. Below, a few of these studies and their results are highlighted to reveal that, while access is important to users, it does not fulfill every need.

Duff and Cherry (2000) conducted a user study on a collection of historical library material with the purpose of comparing user satisfaction across three formats: paper, microfiche, and online (digital). Two findings from their study in particular are interesting. First, they discovered that although 73.9 percent of those surveyed said that the online format was the most useful for them, 41.3 percent said that they like paper best. Roughly 20 percent of people in the study were using online material but preferred original paper material. Those who did choose the paper format as most useful cited reasons such as ease of use/navigation, no need for a machine, and that it provided a sense of the whole document. One comment was, "I want to see the entire package and look through the whole book, [and] may possibly see other interesting articles" (p.20). In contrast, some of the main reasons people did not choose paper as their favorite format had to do with limited access — guarded by cautious archivists, fear of damaging items, convenience, takes a lot of time-for example.

Even more telling were the comments from the open-ended survey questions. When asked to provide reasons for liking the paper format the most, people responded that it was the easiest to read and navigate, gave a better sense of the whole document, and the physicality (authenticity, accuracy, trustworthiness, and completeness) were all important. Some of the comments are worth repeating verbatim (Duff \& Cherry, 2000, p.17):

I feel I've seen the real thing.

Closer to the source; certainly there is no risk of error in transcription; the further one is from original source the more likelihood of problems—also just the physical feel of handling old docs is a pleasure.

\footnotetext{
${ }^{2}$ Newspaper readers tend to only read the first parts of a story —-the first 200 words — and move on to another one before finishing (Fraistat, 2005).
} 


\section{Changes in form modify the content.}

Because I like to look through the whole volume and take notice of the entire text, the binding, other illustrations and publication.

The original medium is the most authoritative and accurate.

Certain to be as complete as possible.

Another user study, on digital cultural heritage resources in New Zealand, produced similar results. Dorner, Liew, and Yeo (2006) found that authenticity of materials and contextualisaton of items were two of their three key findings. Users did not trust what they were seeing on the internet; they wanted verification of authenticity. This could be aided, they said, by detailed contextual information about the material (including papers, photographs, artifacts, etc.) to help them in their interpretation of it. The authors felt that "the importance of gaining a sense of digital materials in their entirety and of understanding the relationships of digital content within the appropriate context was an important issue for many interviewees" (Dorner et al., 2006, p.181).

Perhaps some insight into part of this scenario can be aided by reader response research. Spencer (2006) wanted to know about readers' preferences between printed text and computer screen. She surveyed students (254; average age of 35-39) and found that the preference was for printed material due to its portability, ergonomic reasons (eye strain on computer), and ability to highlight or annotate text. Other reasons were provided in the comments field. Some of these comments follow (Spencer, 2006, p. 44):

\section{...I enjoy the tactile experience of books and paper}

I like paper, it feels and can be more permanent. Paper allows me to be more spontaneous in forming thoughts

...There is something familiar and comforting about holding the information in your hand, marking it up, and making it your own.

In follow-up interviews, the preference was again for paper. Participants cited reliability of the medium, not trusting the Web, and security (being able to hold the text material physically in their hands). One last point of interest came up: some learners felt that their retention rate was affected negatively when reading from a computer screen. To them, reading printed material was an ideal way to absorb information. Overall, respondents seemed to indicate that having a machine in the middle got in the way of their learning. Of note, however, was that most people said they would still want access to the online material—-they wanted both.

In Reading in a Digital Age, Catherine Ross (2002) claims that those who are reading online are not reading at all — that "the new effort to build an electronic library is not about reading at all. It is about the power of electronic searching” (p.7). In other words, in-depth reading, or deep reading is not occurring with digital material (Birkerts, 1994; Liu, 2005; Ross, 
2002). Birkerts, in The Gutenberg Elegies: The Fate of Reading in an Electronic Age, emphasizes pleasurable reading, pointing out that certain behaviors occur when reading a book, summarized by Ross (2002):

...the experience of curling up with a work of literary fiction; the sensory engagement with the physical book, touching it's [sic] binding, turning its pages, inhaling its smell; the way fiction can draw you into a world so that you take up residence in it and it inhabits you long after you close the physical pages of the book. (p. 2)

These two issues - the "real thing" and access — seem to be at the core of what separates digital from original. It appears over and over again, that a.) there is something unique or available in the original material that one cannot get with the digital version - it may be about trustworthiness, authenticity, context, the "feel," or that fact that it is simpler when no machine is involved; and b.) that access, quick and convenient, is the greatest feature of digital material.

\section{Conclusion to part one}

Trickling down from the lessons of the past as well as the issues of the present (digital) are some unique characteristics of the physical material in the context of paper-based knowledge transmission. Notions of materiality, context, touch, and authenticity ("the real thing”) are all tantalizingly alluded to in previous research. In Part Two of this paper (forthcoming), I will explore more deeply the meaning of physical paper-based knowledge transmission in the archival research process. Archives especially are endowed with many layers of physical elements, from the paper, the ink, handwriting versus type, stains, doodles, binding style, and on. They are also unique in that their order and relationship within the sets of other papers and files have meaning. The human-object relationship with these material expressions of communication is rich as well as complex and involves issues of value, meaning, experience and process - all of which are worth inquiring more about as we move ever so rapidly through the current technologically dynamic environment. 


\section{References}

Baker, N. (2001). Double Fold: Libraries and the Assault on Paper. New York: Vintage Books.

Birkerts, S. (1994). Gutenberg Elegies: The Fate of Reading in an Electronic Age. Boston: Faber and Faber.

Brush, S. G. (2005). How Theories Became Knowledge: Why Science Textbooks Should be Saved. In Y. Carignan, et al., (Eds.). Who Wants Yesterday’s Papers? pp. 45-58. Lanham, MD, USA: Scarecrow Press.

Carignan, Y., DuMerer, D., Koutsky, S.K., Lindquist, E., McClurken, K.M., and McElrath, D.P. (2005). Who Wants Yesterday’s Papers? Lanham, MD, USA: Scarecrow Press.

Cherry, J. M., \& Duff, W. M. (2002) Studying digital library users over time: a follow-up survey of Early Canadiana Online. Information Research, 7 (2). Retrieved from http://informationr.net/ir/7-2/infres72.html

Cybulski, W. (2005). Print Collections and Their Possible Futures. In Y. Carignan, et al., (Eds.). Who Wants Yesterday’s Papers? pp.99-114. Lanham, MD, USA: Scarecrow Press.

Deuze, M. (2006). Participation, Remediation, Bricolage: Considering Principal Components of a Digital Culture. The Information Society, 22, 63-75.

Dorner, D.G. Liew, C.L., and Yeo, Y.P. (2006). A Textured Sculpture: The Information Needs of Digitized New Zealand Cultural Heritage Resources. Online Information Review 31(2), 166-184.

Duff, W. M., \& Cherry, J. M. (2000). Use of historical documents in a digital world: comparisons with original materials and microfiche. Information Research, 6(1), Retrieved from http://informationr.net/ir/6-1/paper86.html

Eisenstein, E.L. (1979). The Printing Press as an Agent of Change: Communications and Cultural Transformations in Early-Modern Europe, 2 vols. Cambridge: Cambridge University Press.

Foote, K. E. (1988). Object as memory: The Material Foundations of Human Semiosis. Semiotica, 69(3/4), 243-268.

Fraistat, N. (2005). What Do Books Want? In Y. Carignan, et al., (Eds.). Who Wants Yesterday's Papers? pp. 59-64. Lanham, MD, USA: Scarecrow Press.

Franklin, P. (2005). The Importance of Primary Records. In Y. Carignan, et al., (Eds.). Who Wants Yesterday's Papers? pp.115-122. Lanham, MD, USA: Scarecrow Press.

Lanham, R.A. (1993). The Electronic Word: Democracy, Technology, and the Arts. Chicago: The University of Chicago Press. 
Lindquist, E. (2005). Books and the "Iniquitie or Wearing of Time.” In Y. Carignan et al., (Eds.). Who Wants Yesterday’s Papers? pp. 5-22. Lanham, MD, USA: Scarecrow Press.

Liu, Z. (2005). Reading behavior in the digital environment: Changes in reading behavior over the past ten years. Journal of Documentation, 61(6), 700-712.

Lynch, C. (2001). The Battle to Define the Future of the Book in the Digital World. First Monday, 6(6). Retrieved from http://firstmonday.org/issues/issue6_6/lynch/index.html

McGann J.J. (1991). The Textual Condition. Princeton, N.J.: Princeton University Press.

McLuhan, H.M. (1962). The Gutenberg Galaxy: The Making of Typographic Man. Toronto: University of Toronto Press.

McLuhan, H.M. (1964). Understanding Media: The Extensions of Man. New York: Signet.

McLuhan, H.M. \& Fiore, Q. (1967). The Medium is the Massage: An Inventory of Effects. New York: Bantam Books.

Modern Language Association (1995). Statement on the importance of primary records. Retrieved from http://www.mla.org/resources/documents/rep_primaryrecords/repview_records/primary_r ecords1

Newhagen, J.E. (2005). Above the Fold: The Value of Paper Newspapers. In Y. Carignan et al., Press. (Eds.). Who Wants Yesterday's Papers? pp. 75-89. Lanham, MD, USA: Scarecrow

Ong, W. (1982). Orality and Literacy: The Techologizing of the World. New York, USA: Routledge.

Ross, C. S. (2002). Reading in a Digital Age. In G.E. Gorman, (Ed.). The Digital Factor in Library and Information Services, pp. 91-111. International Yearbook of Library and Information Management. London, UK: Facet Publishing.

Smith, M.N. (2005). Digital Demands vs. Paper Pleas, Introduction. In Y. Carignan et al., (Eds.). Who Wants Yesterday's Papers?, pp. 39-44. Lanham, MD, USA: Scarecrow Press.

Society of American Archivists (2005). Glossary of Archival Terminology. Retrieved from http://www.archivists.org/glossary/index.asp

Spencer, C. (2006). Research on Learners' Preferences for Reading From a Printed Text or From a Computer Screen. Journal of Distance Education 21(1), 33-50. 
Stoker, D. (1999). Should Newspaper Preservation be a Lottery? Journal of Librarianship and Information Science, 31(3), 131-134.

Sun Microsystems (2002). Digital Library Technology Trends. Retrieved from http://www.sun.com/products-n-solutions/edu/whitepapers/pdf/digital_library_trends.pdf

Swan, J. (1988). Information and Madness. Library Journal, 113, 25-28.

Tanselle, G.T. (2005). Uses of Primary Records from the Past. In Y. Carignan et al. (Eds.). Who Wants Yesterday's Papers, pp. 155-162. Lanham, MD, USA: Scarecrow Press.

Toms, E.G., Dufour, C. and Hesemeier, S. (2004). Measuring User’s Experience with Digital Libraries. JCDL, 51-52. 